\title{
A educação como fundamento da percepção ambiental do poder público-judiciário do estado do Tocantins
}

Trata-se de revisão sistemática da literatura, com objetivo de verificar o posicionamento do poder público-judiciário sobre as ações e diretrizes que valorizam e desenvolvem a percepção ambiental deste setor, bem como da sociedade em geral, o que justifica a importância do posicionamento e tomada de decisões perante as interpretações e gargalos que a legislação oferece. O papel da Educação (Ambiental) reforça o alicerce dos níveis de conscientização sendo fundamental para a evolução das práticas destes conceitos. O poder público-judiciário do estado do Tocantins, portanto, configura-se nas premissas levantadas demonstrando alinhamento e perfil de envolvimento com esta conscientização socioambiental. Com isto foi analisado o Relatório de Desempenho do Plano de Logística Sustentável do Poder Judiciário do Tocantins, ano-base 2017, das quais foram analisadas três metas em específico: 1 . Reduzir em $2 \%$ o consumo de copos descartáveis (água e café) no ano de 2017; 2. Reduzir em 10\% os gastos com aquisição de papel em 2016/2017, e, 3. Capacitação socioambiental, sensibilização e comunicação para sustentabilidade. Ainda, foram consultados trabalhos publicados como artigos científicos, dissertações, teses e documentos técnico-científicos para realizar a pesquisa qualitativa sobre a temática abordada. O objetivo deste trabalho foi apresentar a importância do conhecimento acerca da interação entre percepção e educação ambiental considerando o posicionamento do poder público-judiciário. A discussão dos resultados se deu por meio da análise crítica dos autores fundamentada nos dados reportados na literatura.

Palavras-chave: Educação; Percepção Ambiental; Poder Público-Judiciário.

\section{The education foundation of environmental perception of the government-judiciary state of Tocantins}

This is a systematic review of the literature, in order to verify the position of the public-judiciary authorities on the actions and guidelines that value and develop the environmental perception of this sector, as well as society at large, hence the importance of positioning and decision-making vis-à-vis the interpretations and bottlenecks that the legislation offers. The role of education (environmental) reinforces the Foundation of awareness levels being fundamental to the evolution of the practices of these concepts The Government-judiciary State of Tocantins, therefore appears in the premises raised demonstrating alignment and profile of involvement with this social and environmental awareness. To this were consulted works published as scientific papers, dissertations, theses and technical and scientific documents to carry out qualitative research about the topic addressed. With this, the Performance Reports of the Sustainable Logistics Plan of the Judiciary of Tocantins of 2017 were analyzed, of which three specific goals were analyzed: 1 . Reduce by $2 \%$ the consumption of disposable cups (water and coffee) in 2017; 2. Reduce paper purchase spending by $10 \%$ in $2016 / 2017$, and, 3. Socio-environmental training, awareness raising and communication for sustainability. The aim of this work was to present the importance of the knowledge of the interaction between perception and environmental education considering the positioning of the Government-judiciary. The discussion of the results took place through the critical analysis of authors based the data reported in the literature.

Keywords: Education; Environmental Perception; Public-Judicial Power.

Topic: Planejamento, Gestão e Políticas Públicas Ambientais

Reviewed anonymously in the process of blind peer

Maria Leda Melo Lustosa Pereira

Universidade Federal do Tocantins, Brasil http://lattes.cnpq.br/2484522282956896 http://orcid.org/0000-0001-7005-6016

ledamlustosa@uol.com.br

Jadir Alves de Oliveira (iD

Universidade Federal do Tocantins, Brasil http://lattes.cnpq.br/7069375293219142 http://orcid.org/0000-0002-9906-2265 jadiroliveira@gmail.com

Gustavo Paschoal Teixeira de Castro Oliveira (iD) Universidade Federal do Tocantins, Brasil http://lattes.cnpq.br/7410990226412683 http://orcid.org/0000-0002-3045-2097 paschoal@mail.uft.edu.br

DOI: 10.6008/CBPC2318-2881.2019.003.0008
Received: $10 / 09 / 2019$ Approved: 20/11/2019

\author{
José Wilson Rodrigues de Melo (iD \\ Universidade Federal do Tocantins, Brasil \\ http://lattes.cnpq.br/6897023241348861 \\ http://orcid.org/0000-0001-6822-1203 \\ jwilsonrm@mail.uft.edu.br \\ Patrícia Medina (iD) \\ Universidade Federal do Tocantins, Brasil \\ http://lattes.cnpq.br/2860664409387797 \\ http://orcid.org/0000-0003-2110-1989 \\ patriciamedina@uft.edu.br
}

Referencing this:

PEREIRA, M. L. M. L.; OLIVEIRA, J. A.; OLIVEIRA, G. P. T. C.; MELO, J. W. R.; MEDINA, P.. A educação como fundamento da percepção ambiental do poder público-judiciário do estado do Tocantins. Nature and Conservation, v.12, n.3, p.79-90, 2019. DOI:

http://doi.org/10.6008/CBPC2318-2881.2019.003.0008 


\section{INTRODUÇÃO}

Falar de educação ambiental é acima de tudo relacionar o conhecimento como uma construção coletiva em todas as suas instâncias, seja através do conhecimento formal ou não formal. Quando nos referimos à educação ambiental em um contexto macro, pode-se citar a educação para a cidadania, configurando-a como elemento determinante para a consolidação de sujeitos cidadãos. Neste sentido, (PEDRINI, 2010, citado por BATISTA, 2014) ressalta que as "percepções internalizadas em cada indivíduo pode-se buscar a mudança de atitudes, sendo um dos objetivos principais da educação ambiental para sociedades sustentáveis, sendo essa mudança uma consequência possível de ser observada".

Neste contexto, pode-se afirmar que a proteção ao meio ambiente deve estar associada a todas as áreas do desenvolvimento pleno do homem, não se permitindo dissociar os aspectos preservacionistas do ambiente local ou global daqueles mais gerais, relativos às condições políticas, econômicas e culturais dos povos. Tal ideia realiza uma perfeita junção entre equilíbrio do meio ambiente e todos os aspectos da vida do homem em sociedade, inclusive sua dignidade e aspirações por uma vida sem privações.

Representa o reconhecimento do campo do direito ambiental, a necessidade de proporcionalidade, e por consequência, de ponderação, vem recebendo cada vez mais importância, notadamente em virtude do princípio do desenvolvimento sustentável, com uso racional e equilibrado dos recursos naturais, de forma a atender às necessidades das gerações presentes, sem prejudicar o seu emprego pelas gerações futuras.

O aparato legal tem sido uma poderosa ferramenta de transformação da sociedade, uma vez que provoca o debate à cerca das limitações, deveres e direitos dos cidadãos em relação ao meio ambiente. Esta, entre outras razões, pode se constituir na base de um novo paradigma que, por seu turno, implicará em um diferente padrão no relacionamento dos seres humanos com a natureza. 0 estabelecimento de novos procedimentos metodológicos, jurídicos, econômicos ou sociais fortalece as práticas que buscam uma nova forma de administrar o uso dos recursos naturais.

O poder público-judiciário do estado do Tocantins, Tribunal de Justiça (TJ/TO), portanto configura-se nas premissas levantadas demonstrando alinhamento e perfil de envolvimento e conscientização socioambiental. Corroborado a isso o TJ/TO, implantou o Plano de Logística Sustentável 2015-2020 e consiste em práticas de sustentabilidade aplicadas na gestão pública. 0 objetivo deste estudo é apresentar uma reflexão acerca da interação entre percepção e educação ambiental considerando o posicionamento do poder público, principalmente o poder judiciário do estado do Tocantins, enquanto entidade que desenvolve ações com foco socioambiental e econômico.

\section{METODOLOGIA}

A pesquisa para a investigação e estudo deste trabalho constituiu-se de um levantamento qualitativo sobre a temática das questões ambientais e de percepção/educação no contexto do Poder Público-Judiciário do estado do Tocantins. Por meio de base de dados científicos disponíveis em sites eletrônicos, foi realizada a análise do Relatório de Desempenho do Plano de Logística Sustentável do Poder Judiciário do Tocantins 
ano-base 2017, das quais foram analisadas três metas em específico: 1 . Reduzir em $2 \%$ o consumo de copos descartáveis (água e café) no ano de 2017 ; 2. Reduzir em 10\% os gastos com aquisição de papel em 2016/2017; e 3. Capacitação socioambiental, sensibilização e comunicação para sustentabilidade.

A amostra bibliográfica pretendeu analisar situações atuais que retratam nossa sociedade, neste caso, a posição do estado do Tocantins de uma forma macro. Para isso foram consultadas fontes primárias como: artigos científicos, dissertações, monografia, teses, livros e documentos técnico-científicos. Os principais termos utilizados para a pesquisa foram: Percepção Ambiental, Educação, Poder Público, e, Poder Judiciário, Plano de Logística do Tribunal de Justiça/TO.

\section{DISCUSSÃO TEÓRICA}

\section{Papel do Poder Judiciário Brasileiro: Educação Ambiental (EA)}

O doutrinador José Afonso da Silva (2004) afirma que a Constituição da República Federativa do Brasil de 1988 (CF/1988) é a "primeira a tratar deliberadamente da questão ambiental", considerada por profissionais técnicos e científicos como uma "constituição eminentemente ambientalista", assumindo o tratamento da matéria em termos amplos e modernos.

O temo Meio Ambiente, pode ser definido como "(milieu ambiance) foi utilizada pela primeira vez pelo naturalista francês Geoffrey de Saint-Hilaire em sua obra Études progressives d'un naturaliste, de 1835, milieu significa o lugar onde está ou se movimenta um ser vivo, e ambiance designa o que rodeia esse ser." (FREITAS, 2001 citado por MANEIA, et al., 2014). No âmbito jurídico, é difícil definir meio ambiente, pois como bem lembra Milaré (2003), "o meio ambiente pertence a uma daquelas categorias cujo conteúdo é mais facilmente intuído que definível, em virtude da riqueza e complexidade do que encerra".

No Brasil, o conceito legal de meio ambiente encontra-se disposto no artigo 3으, I, da Lei no. 6.938 de 31 de agosto de 1981, dispõe sobre a Política Nacional do Meio Ambiente (PNMA), o qual conceitua meio ambiente: "o conjunto de condições, leis, influências e interações de ordem física, química e biológica, que permite, abriga e rege a vida em todas as suas formas". Trata-se de um conceito restrito ao ambiente natural, sendo inadequado, pois não abrange de maneira ampla todos os bens jurídicos protegidos.

Por conseguinte, o Artigo 225 da CF/1988, aborda o "direito ao meio ambiente ecologicamente equilibrado, bem de uso comum do povo e essencial à sadia qualidade de vida, impondo-se ao Poder Público e à coletividade o dever de defendê-lo e preservá-lo para as presentes e futuras gerações". O poder judiciário, no entanto, pode ser evidenciado neste contexto, pois lidera significativamente a gestão das esferas de governo e consequente os níveis de atuação na escala de tempo e espaço da ação humana. Por outro lado, o inciso VI deste artigo incube ao poder público "promover a educação ambiental em todos os níveis de ensino e a conscientização pública para a preservação do meio ambiente'. Em contrapeso o parágrafo 3ㅇ do referendado artigo 225 imputa aos sujeitos infratores relativas "as condutas e atividades consideradas lesivas ao meio ambiente, sejam estas pessoas físicas ou jurídicas, a sanções penais e administrativas, independentemente da obrigação de reparar os danos causados". 
Entende-se que em relação à defesa ao meio ambiente, as medidas ambientais devem ser propostas diante de qualquer ato que possa trazer algum impacto ambiental. Porém, é necessário o amadurecimento da percepção do próprio poder judiciário para a realização adequada desta conduta. A atuação da Educação ambiental vai além da abordagem da Política Nacional de Meio Ambiente (PNMA), pois está focada na capacitação da sociedade civil, de modo a contribuir para a "participação ativa na defesa da qualidade do meio ambiente", conforme determina o artigo 13 da Lei n 9.795 de 27 de abril de 1999, Lei está que implantou a Política Nacional de Educação Ambiental (PNEA), em seguida regulamentada pelo Decreto no 4.281 de 25 de junho de 2002.

Nesse passo, destaca-se a obrigação constitucionalmente imposta ao Poder Público de preservar o meio ambiente, devendo tal incumbência ser exercida nas três esferas do Poder Estatal. Assim, o preceito constitucional ditado no artigo 225 da Constituição Federal impõe aos Poderes Executivo, Legislativo e Judiciário a tutela da preservação e proteção ao meio ambiente. Quanto às questões ambientais, é inevitável reconhecer que já existe um compromisso constitucional e uma normatividade ampla voltada para a proteção do ambiente e salvaguarda da sadia qualidade de vida.

Por sua vez, o próprio Supremo Tribunal Federal já afirmou a existência de um direito fundamental ao meio ambiente como de terceira dimensão, entendimento consolidado no julgamento do MS no 22.164 SP/1995, Relator Ministro Celso de Mello, como específica:

[...] A questão do direito ao meio ambiente ecologicamente equilibrado - direito de terceira geração - princípio da solidariedade - o direito a integridade do meio ambiente - típico direito de terceira geração - constitui prerrogativa jurídica de titularidade coletiva, refletindo, dentro do processo de afirmação dos direitos humanos, a expressão significativa de um poder atribuído, não ao indivíduo identificado em sua singularidade, mas, num sentido verdadeiramente mais abrangente, a própria coletividade social. Enquanto os direitos de primeira geração (direitos civis e políticos) - que compreendem as liberdades clássicas, negativas ou formais - realçam o princípio da liberdade e os direitos de segunda geração (direitos econômicos, sociais e culturais) - que se identifica com as liberdades positivas, reais ou concretas - acentuam o princípio da igualdade, os direitos de terceira geração, que materializam poderes de titularidade coletiva atribuídos genericamente a todas as formações sociais, consagram o princípio da solidariedade e constituem um momento importante no processo de desenvolvimento, expansão e reconhecimento dos direitos humanos, caracterizados, enquanto valores fundamentais indisponíveis, pela nota de uma essencial inexauribilidade.

O Poder Judiciário é responsável pela resolução dos embates sociais através da função jurisdicional que consiste na "aplicação da lei de forma coativa, substituindo as vontades das partes, compondo os conflitos ou resistências ao cumprimento das leis" (ROSA, 2009). Entretanto, ao mesmo tempo, é urgente e necessário à implementação de políticas públicas nessa área, seja porque os órgãos estatais estão insuficientemente equipados ou diante das dificuldades da realidade político-administrativa ou de interesses econômicos que terminam prevalecendo. No cenário ambiental, é visível o descompasso existente entre os avanços exigidos pelas novas demandas da sociedade e a forma e o resultado das prestações estatais, sobretudo no que toca ao desenvolvimento de políticas públicas.

Logo, o perfil transformador da jurisdição ambiental, pautado na necessidade de atribuição de deveres fundamentais e no princípio da solidariedade, não pode ficar refém da inércia governamental, muito menos atado aos caprichos políticos que gravitam na chefia do Executivo, devendo nortear a implementação 
das normas ambientais e imputar as responsabilidades próprias do Poder Público.

Esse papel do Poder Público deve estar preferencialmente circunstanciado na prevenção ao dano, na certeza de que os desgastes ambientais normalmente são irreversíveis, tendo como norte o princípio da precaução e da prevenção. Daí porque o uso da tutela provisória de urgência, com relevante destaque conferido pelo artigo 9o do Novo Código de Processo Civil (Lei no 13.105/2015), ganha especial importância nas ações de natureza ambiental, em que os riscos envolvidos exigem do Judiciário o enfrentamento rápido de questões urgentes, muitas vezes antes mesmos que o contraditório tenha se formado no processo.

De fato, diversos são os danos causados ao meio ambiente que o Poder Público, por ação ou omissão, possa direta ou indiretamente contribuir, muitas vezes em razão da ineficácia ou completa ausência de elaboração e implementação de políticas públicas na área ambiental, a exemplo: a) a poluição de rios e mares pelo lançamento de esgotos urbanos e industriais sem o devido tratamento; b) o descaso com a proteção das espécimes vegetais e animais, principalmente aquelas que estejam em extinção; c) o abandono de bens integrantes do patrimônio cultural brasileiro, c) a degradação de ecossistemas e áreas naturais de relevância ecológica; d) o depósito e a destinação final inadequados de lixo urbano, entre outros.

Necessita, portanto, adotar técnicas de gestão para atender a sua finalidade de uma maneira eficiente, eficaz e, por conseguinte, efetiva. A visão de uma Justiça lenta e ineficiente é algo que vem sendo combatido pelo Conselho Nacional de Justiça (CNJ), órgão criado pela Emenda Constitucional no 45/2004, popularmente conhecida por "Reforma do Judiciário" (BRASIL, 1988).

Usualmente o papel do Estado é visto através dos instrumentos e neste ponto devemos entrar mais a fundo nos conceitos da gestão ambiental pública, pois atualmente já há conceitos e modelos bem desenvolvidos de Sistemas de Gestão Ambiental (SGA) para organizações, com um foco em empresas, porém alguns dos princípios dos mesmos podem ser focados em um Tribunal de Justiça, por exemplo.

Dessa forma, o ativismo judicial se ergue principalmente ligado aos direitos fundamentais de segunda geração (econômicos, sociais e políticos), aqueles que ordenam uma conduta positiva do Estado. A ausência de regulação de tais direitos não impede o julgador de reconhecê-los e, se for o caso, de determinar a autoridade de tais preceitos, sempre à luz da dignidade da pessoa humana. Caberá, contudo, ao operador do direito, promover o exercício de ponderação, com parcimônia, para compatibilizar não só a proteção do meio ambiente, dada sua importância para a humanidade.

\section{Formação da Conscientização Ambiental}

No Brasil, nos últimos anos, o tema que mais se destacou em matéria ambiental, foi "escassez" ou "sustentabilidade dos recursos naturais" e recentemente "injustiça ambiental" (CUNHA et al., 2014). Neste sentido, Cunha et al. (2014), afirmam:

nos últimos anos, movimentos sociais e acadêmicos passaram a se dedicar às questões ligadas à justiça ambiental, o que resultou, em 2001, na criação da Rede Brasileira de Justiça Ambiental (RBJA), uma ONG com sede no Rio de Janeiro e que luta contra o racismo ambiental. A Rede Brasileira de Justiça Ambiental (RBJA) é resultado de um projeto desenvolvido em conjunto pela Fundação Oswaldo Cruz (Fiocruz) e pela Fase Solidariedade e Educação, com o apoio do Departamento de Saúde Ambiental e Saúde do 
Trabalhador do Ministério da Saúde, com o objetivo de apoiar a luta de muitas populações e grupos atingidos em seus territórios por projetos e políticas baseados numa visão de desenvolvimento considerada insustentável.

Para transformar a sociedade e torná-la sustentável são pertinentes mudanças significativas na cultura predominante, bastante arraigada ao modo de produção vigente. As transformações devem ocorrer na consciência dos cidadãos no seu modo de vida e no consumo. Por isso, a Educação Ambiental desenvolve a autonomia e o saber ambiental nos sujeitos contra a ideia do desenvolvimento produtivo ilimitado como cerne do ser humano. A EA não é exclusiva para a juventude, mas mudanças nascem normalmente de um processo de educação transformadora e revolucionária, sendo que os atores, os protagonistas que agem, participam e realizam estas ações historicamente são os jovens, razão da importância desses sujeitos para a educação ambiental.

Entende-se como imprescindível a formação dos agentes construtores da educação, entretanto, é necessário haver a capacitação adequada dos agentes na formação para ambos os tipos de educação, já que muitos deles encontram dificuldades para vivenciar na prática o encontro das duas culturas educacionais, razão pela qual,“[...] percebe-se que ainda hoje, mesmo com a valorização dos espaços de educação não formal, a formação para atuar de maneira coletiva com os dois espaços é escassa" (CATARINO et al., 2017).

Quando se analisa a questão do espaço onde são desenvolvidos os processos de educação formal e não formal, se depara com a ideia incipiente e segregadora de que a educação formal é realizada apenas em espaço de instituições formais "a escola em todos os seus níveis, da educação infantil ao ensino superior" e a não formal em espaços de instituições não formais (RIBEIRO, 2017).

Observa-se, no caso do ensino da EA, é a necessidade de troca de conhecimento entre os profissionais educadores das disciplinas científicas, que deve ser objetivo das articulações e das relações multidisciplinares. Segundo Leff (2011) a "[...] interdisciplinaridade implica assim um processo de interrelação de processos, conhecimento e práticas que [...] transcende o campo da pesquisa e do ensino no que se refere estritamente às disciplinas científicas e suas articulações". Além disso, a CF/1988, em seu Art. 255, outorga a necessidade de se promover a EA e a conscientização de preservação ambiental.

A transversalidade consta nas diretrizes do Programa Nacional de Educação Ambiental - ProNEA juntamente com a interdisciplinaridade, sendo que esta última, para Leff (2011), deva ser superada pela transdisciplinaridade que difere ainda da transversalidade nas suas abordagens metodológicas. Esses conceitos, de certo modo, levam em conta ainda a organização disciplinar, já que a transversalidade deve ser construída com base na perspectiva Inter e transdisciplinar.

Aspectos reducionistas e de percepção prematura detectados nos inquiridos, retratam a necessidade de haver intensificação neste programa a fim de promover mudanças no nível de conhecimento sobre os assuntos ambientais, e transformações no comportamento dos alunos (ADORNO et al., 1985). Pode-se especular, portanto, se, estes não são exemplo da formação cultural alimentada pela semi-formação com foco na ideia ilusória da ascensão social pela cultura, conforme visto em Adorno (1996). Nesta situação, a reflexão proposta por Silva et al. (2012), em relação à inversão de papeis entre pais e filhos, tem os filhos o papel de influenciar os seus pais para transformar a cultura destes, possivelmente impregnada de valores 
contraditórios àqueles de caráter socioambiental.

Por tal razão, a percepção ambiental se inclui neste estudo por ser um tema do campo da educação ambiental mesmo que considerado recente. A partir da Conferência das Nações Unidas sobre o Meio Ambiente e Desenvolvimento Sustentável (ECO-92), foi realizado todo um trabalho das organizações não governamentais, de direitos humanos e mesmo algumas organizações empresariais, voltado à sensibilização para que as questões ambientais fossem inseridas nas agendas governamentais e seu vocabulário estivesse disponível à sociedade (BRASIL, 2006).

Silva et al. (2012) provoca os estudiosos e os governantes ao sugerir que, para melhor subsidiar as políticas públicas voltadas à juventude, se faz necessário que as pesquisas da relação juventude e o ambiente se aprofundem e venham a contribuir para um melhor entendimento da percepção ambiental haja vista os problemas. Este pesquisador sugere maior investimento nesse tipo de pesquisa com intuito de ampliar a identificação dos discursos e práticas dos jovens em um mundo de rápidas transformações, trazendo como justificativa que com a percepção socioambiental pode sugerir alternativas à sensibilização.

Observa-se que, neste entendimento, o autor relaciona percepção ambiental com consciência ambiental, o que não traz luz para a compreensão do assunto, pois consciência também é termo complexo e alvo de estudos na psicologia e filosofia. Lembrando que a representação social é o fenômeno que melhor abarca esta complexidade da dinâmica ambiental, pois consegue acompanhá-la formando uma nova representação social da reconstrução de um senso coletivo e comum das noções de meio ambiente (SETTON, 2002).

Desta forma, promover as mudanças necessárias nos sujeitos, sobretudo os donos dos meios de produção, deveriam promover transformações culturais de consumo através da EA, pois, seu papel de agente difusor de conhecimento tem como objetivo primordial a "[...] mudança dos hábitos e comportamentos considerados predatórios, em hábitos e comportamentos tidos como compatíveis com a preservação dos recursos naturais" (SATO, 2004) que resguardem valores imensuráveis como a preservação do ambiente ecologicamente correto.

\section{Tribunal de Justiça do Estado do Tocantins: Práticas de Sustentabilidade Socioambiental}

O Poder Judiciário do estado do Tocantins procura atuar fundamentado no conhecimento, além de aplicar a legislação já existente de forma eficaz com autuação, fiscalização, monitoramento e punição. Contudo, essas leis só possuem efeito concreto quando o poder judiciário e o poder público se apresentam com um posicionamento fundamentado em educação ambiental no contexto em que este está inserido.

No âmbito do Tribunal de Justiça do Tocantins (TJ/TO) vinculado ao Planejamento Estratégico 20152020, foi elaborado o Plano de Logística Sustentável (PLS), com objetivos e responsabilidades definidas, que permitem "estabelecer e acompanhar práticas de sustentabilidades, racionalização que objetivem uma melhor eficiência do gasto público e da gestão dos processos de trabalho, considerando a visão sistêmica do órgão" (TOCANTINS, 2017).

Os Planos de Logística Sustentável (PLS) são ferramentas de planejamento que permitem aos órgãos 
ou entidades estabelecer práticas de sustentabilidade e racionalização de gastos e processos na Administração Pública. A Instrução Normativa no 10, publicada no dia 14 de novembro de 2012, Diário Oficial da União, estabelece as regras para elaboração dos Planos de Gestão de Logística Sustentável que cada Estado pode executar em sua administração. Esses Planos foram criados pelo art. 16, do Decreto № 7.746, de 5 de junho de 2012, Secretaria de Logística e Tecnologia da Informação.

A implantação do Plano de Logística Sustentável do Poder Judiciário do Estado do Tocantins (PLSPJTO) apresenta as competências nas unidades socioambientais nos órgãos e conselhos por meio da Resolução n. 201/2015 do Conselho Nacional de Justiça-CNJ. A Resolução n. 22/2015-TJTO, por sua vez, publicada no Diário da Justiça n. 3637, de 12 de agosto de 2015, instituiu o Núcleo de Gestão Socioambiental. Considera-se este marco de alto significativo, pois as demandas são geridas pela Diretoria Geral e à Presidência do Tribunal de Justiça.

Neste contexto, levando-se em consideração as práticas de sustentabilidade, serão apresentadas três metas contidas no plano (2017), que são: 1) Redução do uso de papel/impressão, e 2) Redução do uso de copos descartáveis para água e café; e, 3) Capacitação socioambiental, sensibilização e comunicação para sustentabilidade.

A primeira tem como objetivo o "monitoramento do consumo geral de papel em razão da implantação do Processo Judicial Eletrônico (Lei n. 11419/2006 e Resolução CNJ n. 185/2013) e da implantação dos processos administrativos eletrônicos" (TOCANTINS, 2017). Conforme aponta o relatório, "o papel adquirido não é reciclado, mas somente reciclável oriundo de florestas $100 \%$ plantadas e renováveis" (TOCANTINS, 2017).

A segunda meta proposta é em relação ao uso do copo descartável, "objetiva o monitoramento da geração de resíduos oriundos do consumo de copos descartáveis, de plástico ou outros materiais e o uso racional dos recursos econômicos." (TOCANTINS, 2017) e a terceira meta tem por objetivo produzir conhecimento sobre sustentabilidade; sensibilizar o corpo funcional acerca da temática; e contribuir para instituição da política ambiental. O TJ/TO apresenta medidas efetivas para o alcance de uma cultura socioambiental em todo sistema do Tribunal de Justiça no estado do Tocantins.

Para tanto, desenvolve ações de formação dos servidores com temas relacionados à educação socioambiental, como: capacitação e sensibilização do corpo funcional em ações sobre educação socioambiental (cursos em EaD ou presenciais, grupos de estudo, seminários, semana do meio ambiente, oficinas, campanhas, outros). Foram realizados também, seminários, relacionados à temática como: $\mathrm{X}$ Diálogo Ambiental, Constitucional e Internacional; VI Congresso Internacional - Workshop Crimes Ambientais como Crimes Contra a Humanidade, sendo estas ações abertas à comunidade acadêmica e em geral a todas as pessoas que queiram participar.

Ressaltando que as ações de formação para magistrados, servidores e comunidade são desenvolvidas pela Escola Superior da Magistratura Tocantinense (ESMAT/TO) e pelo Centro de Educação Infantil Nicolas Quagliariello Vêncio (CEI), sendo uma referência estadual e internacional no campo de educação.

Outra ação de cunho social de alcance amplo para a sociedade em geral é o Projeto Diálogos da 
Sustentabilidade - trata-se de uma parceria firmada pelo TJ/TO com a Rádio CBN Tocantins, faculdades e outros órgãos públicos para realização do projeto. Segundo se apresenta no relatório em análise (TOCANTINS, 2017), o objetivo é discutir temas acerca da "sustentabilidade e de interesse público". Foram seis etapas, com temas diferentes, e os debates produzidos foram gravados e transformados em programas de uma hora, posteriormente transmitidos pela Rádio CBN Tocantins.

Nos termos do relatório de desempenho do Plano de Logística Sustentável do Poder Judiciário do Tocantins ano-base 2017, as ações de cunho socioambiental previstas no referido plano, pode-se ter como exemplo a ser utilizado por outros órgãos, públicos ou privados, objetivando uma melhor eficiência do gasto público ou privado e da gestão dos processos de trabalho, considerando a visão sistêmica do órgão ou da empresa.

A relação entre meio ambiente e educação para a cidadania assume um papel cada vez mais desafiador, demandando a emergência de novos saberes para apreender processos sociais que se complexificam e riscos ambientais que se intensificam. As políticas ambientais e os programas educativos relacionados à conscientização da crise ambiental demandam cada vez mais novos enfoques integradores de uma realidade contraditória e geradora de desigualdades, que transcendem a mera aplicação dos conhecimentos científicos e tecnológicos disponíveis.

Quando nos referimos à educação ambiental, situam-na em contexto mais amplo, o da educação para a cidadania, configurando-a como elemento determinante para a consolidação de sujeitos cidadãos. Neste caso, o princípio de proteção ao meio ambiente como interesse coletivo, a fim de não ferir os ditames constitucionais e ocasionarmos inúmeras injustiças. Ainda que a legislação ambiental brasileira, tida como avançada, poderia ser a grande base de sustentação. Todavia, os entraves na aplicação das leis, bem como a adoção de providências técnicas mais concretas em relação aos problemas ambientais, são imensos.

Nesse contexto, nos dias atuais, parte significativa da sociedade, bem como a postura do poder público-judiciário passou a tomar consciência da necessidade de mudanças. Como bem demonstra as ações analisadas no Plano de Logística Sustentável do TJ/TO (2017), temas aplicados nas seguintes categorias: copos descartáveis (água/café); papel/impressão e sensibilização por meio de capacitações socioambientais. Os resultados deste monitoramento de gestão de consumo e melhoria de qualidade de vida estão descritos na tabela a seguir.

Tabela 1: Dados de monitoramento de gestão de consumo sustentável.

\begin{tabular}{|l|l|c|c|}
\hline Item & \multicolumn{1}{|c|}{ Indicador / Atividade } & \multicolumn{2}{|c|}{ Ano/Unidade } \\
\cline { 3 - 4 } & & $\mathbf{2 0 1 6}$ & $\mathbf{2 0 1 7}$ \\
\hline 1 & Consumo de copos descartáveis totais (água e café) & 29.610 & 32.313 \\
\hline 2 & Impressão/Papel & 14.834 & 16.160 \\
\hline 3 & Ações de Capacitação/Sensibilização & 1.036 & 1.651 \\
\hline
\end{tabular}

Fonte: Relatório de Desempenho do Plano de Logística Sustentável do Poder Judiciário do Tocantins, ano-base 2017.

O monitoramento da geração de resíduos oriundos do consumo de copos descartáveis, de plástico ou outros materiais apresenta indícios de uso racional dos recursos econômicos, embora se observou um aumento em 2017, o qual, em tese, se justifica pelo número de atividades relacionados a capacitação que teve um aumento significativo no mesmo ano. Ações de campanhas de sensibilização do corpo funcional, a 
implementação de pontos estratégicos para distribuição de café e a distribuição de canecas permanentes ao corpo funcional, são práticas registradas no relatório.

Em relação ao consumo geral de papel (impressão), ainda apresentou aumento de 2016 para 2017, mesmo com a implantação do Processo Judicial Eletrônico (Lei no 11419/2006 e Resolução CNJ no 185/2013) e dos processos administrativos eletrônicos. A adoção do sistema de controle de impressões (Outsourcing) e implementação das ilhas de impressão em pontos estratégicos foram ações implementadas para que haja a redução. O relatório aponta que o TJ/TO optou por consumir papel reciclado.

As capacitações socioambientais (cursos EaD ou presenciais, grupos de estudo, seminários, semana do meio ambiente, oficinas, campanhas entre outras ações) vêm para desenvolver a qualidade de vida por meio de ações educacionais relacionadas aos temas propostos no PLS (2017). Este monitoramento e a participação do corpo funcional em ações de capacitação e sensibilização relacionadas ao tema de sustentabilidade são fundamentais para subsidiar a tomada de decisões quanto ao estímulo dessas temáticas. Observa-se, um acréscimo significativo na participação dos servidores e considerando o conhecimento prático adquirido podem ser aplicados na rotina profissional, bem como nas respectivas demandas domésticas.

Uma capacitação sugerida nesse estudo seria a A3P - Agenda Ambiental na Administração Pública que pode ser aplicada em quaisquer órgãos das esferas governamentais. Esta agenda tem como proposta promover a sensibilização dos servidores públicos quanto ao combate do desperdício de recursos naturais, materiais de expediente e melhoria da qualidade de vida no ambiente de trabalho.

Sabendo que todas as atividades realizadas pelo homem, gastam e depreciam recursos naturais, como indicados nos dados do PLS (2017) relacionados ao combustível, obras, peças de frota de carros para serviços e magistrados. No Tocantins, ainda não há uso de combustíveis renováveis, embora já exista um aparato legal que aborda o uso de painéis solares em estabelecimentos públicos para redução de energia elétrica.

Os resíduos oriundos do consumo de água mineral envasada, por exemplo, em que as embalagens plásticas são descartáveis podem ser amplamente reduzidos por filtros comuns de carvão ativado paras todos os servidores do Estado, bem como do poder público judiciário. Outro fator importante é que foi firmado convênio com a Cooperativa de Catadores de Recicláveis de Palmas (COOPERAN), para recolhimento dos resíduos, haja vista a ausência de um Programa de Coleta Seletiva Efetivo para todo o Estado, bem como para o Tribunal de Justiça. A Lei 12.305/2012, Decreto Federal 5.940/2006, Decreto Federal 7.404/2010, ABNT NBR 10.004/2004, Resolução Anvisa 358/2005 ser refere ao aparelho legal de todos os resíduos, e neste momento as ações que são efetivas são o estímulo à redução do consumo e a destinação correta.

\section{CONCLUSÕES}

A questão da educação ambiental não é só de responsabilidade do poder público, e sim é de responsabilidade de todas as nações, é uma responsabilidade mundial. A falta de desconhecimento dos problemas ambientais pelas gerações presentes, ainda, pode-se dizer que existem, mesmo diante de toda 
extensão mundial de informação através da internet.

A educação ambiental deve ser capaz de alcançar todas as gerações de forma individual, coletiva e integrada. Como fazer?. O caminho ainda deve ser local, começando pela própria comunidade, pelo local de trabalho, [...], pequenas ações que poderão ser desenvolvidas para evitar grandes tragédias mundiais, como por exemplo, o plástico doméstico que está se alastrando pelo mundo através dos rios e oceanos.

Diante dos aspectos observados no estudo, foi possível verificar as fragilidades na estrutura da Educação Ambiental, no entanto, o Poder Judiciário do TO, apresenta o plano de logística sustentável desenvolvido pelo órgão, com ações passíveis de serem implementadas como modelo de gestão socioambiental em outras instituições, de forma geral.

A proposta de nível de consciência ambiental não está pronta e acabada, esta análise deve ser aprofundada para que ocorra também uma releitura nestas classificações de visão ambiental, com foco no auxílio da promoção de uma educação ambiental transformadora para a conscientização dos indivíduos, pelo processo de formação da cultura ambiental. É possível identificar possíveis pistas que levam a inferir uma provável necessidade de uma reorganização pedagógica da Educação Ambiental para melhoria do desenvolvimento do processo de formação da cultura ambiental.

O que leva a crer, que as ações que estão sendo desenvolvido pelo TJ/TO, através de um processo de formação continuada, de implementações de mudanças de comportamento, como o uso de copo permanente, no ambiente de trabalho, além das informações repassadas através da rádio, um instrumento de comunicação ainda utilizado por muitas comunidades é o caminho para uma educação socioambiental que poderá trazer resultados positivos para as gerações presentes e futuras.

Por último, este estudo se mostra necessário, uma vez que divulga os resultados de ações positivas desenvolvidas por um órgão público que se preocupa com práticas de sustentabilidades, racionalização, eficiência do gasto público e da gestão dos processos de trabalho, comprometendo-se com as questões socioambientais e a responsabilidade social.

\section{REFERÊNCIAS}

ADORNO, T. W.. Teoria da Semicultura. Revista Educação e Sociedade, v.56, n.17, p.388-411, 1996.

ADORNO, T. W.; HORKHEIMER, M.. Dialética do esclarecimento: fragmentos filosóficos. Rio de Janeiro: Jorge Zahar, 1985.

BATISTA, A. C.. Percepção e educação ambiental na gestão pública de recursos hídricos. 2014. Monografia (PósGraduação em Gestão Ambiental nos Municípios) Universidade Tecnológica Federal do Paraná, Campus Medianeira, 2014.

BRASIL. Lei n. 6.938, de 31 de outubro de 1981. Dispõe sobre a Política Nacional do Meio Ambiente. Brasília: DOU, 1981.

BRASIL. Constituição (1988). Constituição da República Federativa do Brasil. Brasília: DOU, 1988.
BRASIL. Decreto n. 4.281, de 25 de junho de 2002. Regulamenta a Lei n. 9.795, de 27 de abril de 1999, que institui a Política Nacional de Educação Ambiental, e dá outras providências. Brasília: DOU, 2002.

BRASIL. Lei n. 9.795, de 27 de abril de 1999. Institui a Política Nacional de Educação Ambiental. Brasília: DOU, 1999.

BRASIL. Decreto n. 4.281, de 25 de junho de 2002. Regulamenta a Lei n. 9.795, de 27 de abril de 1999, que institui a Política Nacional de Educação Ambiental. Brasília: DOU, 2002

BRASIL. Lei n. 13.105, de 16 de março de 2015. Novo Código de Processo Civil. Brasília: DOU, 2015.

CATARINO, G. F. C.; QUEIROZ, G. R. P. C.; LIMA, M. C. A. B.. O formal, o não formal e as outras formas: a aula de física como gênero discursivo. Revista Brasileira de Educação 
v.22, n.69, p.499-517, 2017.

CUNHA, B. P.; AUGUSTIN, S.. Sustentabilidade ambiental: estudos jurídicos e sociais. Caxias do Sul: Educs, 2014.

LEFF, H.. Complexidade, interdisciplinaridade e saber ambiental. Revista Olhar do professor, Ponta Grossa, v.14, n.2, 2011. DOI:

http://doi.org/10.5212/OlharProfr.v.14i2.0007

MANEIA, A.; CARMO, W.; KROHLING, A.. Meio ambiente e cidadania: uma perspectiva sobre o desenvolvimento sustentável. Revista Eletrônica em Gestão, Educação e Tecnologia Ambiental: REGET, v.18, n.1, p.220-227, 2014.

MILARÉ, E.. Direito do ambiente. 3 ed. São Paulo: Revista dos Tribunais, 2003.

ROSA, M. F. E.. Direito Administrativo: Estado, Administração Pública e outros temas (Coleção sinopses jurídicas, v. 19).10 ed. São Paulo: Saraiva, 2009.
RIBEIRO, A. C.. Meio ambiente e Educação: Percepção Ambiental de jovens alunos a cerva da água. Dissertação (Programa de pós-graduação em educação) - Universidade Federal de Goiás, Goiânia, 2017.

SETTON, M. G. J.. Família, escola e mídia: um campo com novas configurações. Educação e Pesquisa, São Paulo, v.28, n.1, p.107-116, 2002.

SILVA, R. C.; BARKI, T. V. P.. Compras públicas compartilhadas: a prática das licitações sustentáveis. Revista do Serviço Público Brasília, v.63, n.2, 2012. DOI: https://doi.org/10.21874/rsp.v63i2.93

SILVA, J. A.. Direito ambiental constitucional. 5 ed. São Paulo: Malheiros, 2004

TOCANTINS. Relatório de Desempenho do Plano de Logística Sustentável do Poder Judiciário do Tocantins (anobase 2017). Palmas: Tribunal de Justiça do Tocantins, 2017.

A CBPC - Companhia Brasileira de Produção Científica (CNPJ: 11.221.422/0001-03) detém os direitos materiais desta publicação. Os direitos referem-se à publicação do trabalho em qualquer parte do mundo, incluindo os direitos às renovações, expansões e disseminações da contribuição, bem como outros direitos subsidiários. Todos os trabalhos publicados eletronicamente poderão posteriormente ser publicados em coletâneas impressas sob coordenação da Sustenere Publishing, da Companhia Brasileira de Produção Científica e seus parceiros autorizados. Os (as) autores (as) preservam os direitos autorais, mas não têm permissão para a publicação da contribuição em outro meio, impresso ou digital, em português ou em tradução. 